\title{
Preservative and antimicrobial susceptibility of non-fermenting bacilli recovered from solid waste of beauty salons in Brazil
}

\author{
Rafael Xavier Martins ${ }^{1}$, Andrwey Augusto Galvão Viana ${ }^{1}$, Gilanna Falcão Ferreira ${ }^{1}$, Thiago Gonçalves Cavalcanti ${ }^{1}$, Ian \\ Porto Gurgel do Amaral ${ }^{2}$, Rafael de Almeida Travassos ${ }^{3}$, Ulrich Vasconcelos ${ }^{4^{*}}$ \\ ${ }^{1}$ Universidade Federal da Paraíba, Laboratório de Microbiologia Ambiental, Campus-I, João Pessoa, PB, Brazil. \\ ${ }^{2}$ Universidade Federal da Paraíba, Laboratório de Biotecnologia de Organismos Aquáticos, Campus-I, João Pessoa, PB, Brazil. \\ ${ }^{3}$ Universidade Federal da Paraíba, Laboratório de Farmacobiotecnologia, Campus-I, João Pessoa, PB, Brazil. \\ ${ }^{4}$ Universidade Federal da Paraíba, Centro de Biotecnologia, Laboratório de Microbiologia Ambiental, Campus I, CEP-58.051-900, Castelo Branco, João \\ Pessoa-PB, Brazil.
}

\section{ARTICLE INFO \\ Article history: \\ Received on: 04/04/2018 \\ Accepted on: 09/05/2018 \\ Available online: 29/06/2018}

\section{Key words:}

Urban Pollution, Cosmetics,

Hair care products,

Multidrug-resistance, Paraíba.

\begin{abstract}
This work aimed to isolate Non-fermenting Gram-Negative Bacilli (NFGNB) from packages of hair care products, discarded as common solid waste by beauty salons and to assess their susceptibility to antibiotics and preservatives. Samples from hair care products were collected during eight weeks from seven salons in the metropolitan area of the city of João Pessoa, Brazil. Twelve NFGNB were recovered and subjected to biochemical identification and susceptibility testing. Species of the genus Burkholderia were more frequent, followed by Pseudomonas and Aeromonas. The highest antibiotic resistance rates were observed among quinolones, meropenem, and sulfonamide. Six isolates showed multidrug-resistance profile and survived different concentrations of parabens, imidazolidinyl urea, and triclosan. However, no correlation between resistance to antibiotics and the preservatives was found. Multidrug-resistant opportunistic pathogenic species found in the material remaining inside the used packages may represent a risk to human health and to the environment when discarded improperly with normal household waste.
\end{abstract}

\section{INTRODUCTION}

Due to the expanding influence of the beauty industry over the last decade, Brazil has experienced an increase in the number of beauty salons. These establishments dealing with cosmetics treatment as well as provide extended services related to the use of several chemicals (Nkansah et al., 2016). Cosmetics and personal care products (CPCPs) are commodities formulated in order to cleanse, mask and correct imperfections, real or imaginary, and are therefore related to positive human emotions and rather than being considered as relating to environmental issues by most users (ANVISA, 2005). However, CPCPs may affect the environment in two ways: (1) by the nature of the

${ }^{*}$ Corresponding Author

Ulrich Vasconcelos, Universidade Federal da Paraiba, Centro de Biotecnologia, Laboratório de Microbiologia Ambiental, Campus I, CEP-58.051-900, Castelo Branco, João Pessoa-PB, Brazil.

E-mail:u.vasconcelos@ cbiotec.ufpb.br substances themselves, as yet an underexplored theme and; (2) by means of the generation of packaging waste (Zulaikha et al., 2015; Fendall and Sewell, 2009).

As they are products for external use, CPCPs are designed to last since they must maintain their organoleptic and/ or cosmeceutical characteristics for consumption up to 36 months (Bu et al., 2013). However, many substances included in the formulations can be used as nutritional sources for microorganisms, requiring the use of different classes of preservatives in order to prevent spoilage of a product during its lifetime (Flores et al., 1997). In addition, certain compounds may easily be decomposed by microorganisms, thus releasing toxic substances into the environment (Xu et al., 2009).

Although CPCPs are not required to be sterile preparations, when opened, all cosmetic products are subjected to secondary contamination from the handler microbiota or from the storage environment (Zapka et al., 2011). Biological contaminants in cosmetics may include pathogenic organisms, opportunistic 
pathogens and saprophytes, particularly Non-fermenting GramNegative Bacilli - NFGNB (Shaqra et al., 2014). Microbial contamination from cosmetics is a global concern with possible negative economic consequences as well as risks to public health, when considering the potentials for product loss integrity, consumer infection, and the onset of microbial multidrugresistance phenomenon, due to the resilience of preservatives present in the formulations (Lin et al., 2010; Richardson, 2007).

In Brazil, the cosmetics industry generates nearly US\$ 110 billion, growing on average by $10 \%$ each year, and taking the $7^{\text {th }}$ position as producer, $24^{\text {th }}$ as exporter and $3^{\text {rd }}$ as a global consumer, particularly of hair care products, makeup and for oral hygiene and personal care (ABIHPEC, 2018). The most consumed CPCPs are intended for the treatment of hair, representing an increase of $38.2 \%$ in sales of these inputs in one year alone. Most CPCPs costumers in Brazil are women visiting beauty salons at least once a week, representing in the last 10 years an increase in consumption in all social classes: $84 \%$ (A and B), 78\% (C) and 63\% (D and E) (IBOPE, 2017).

In many beauty salons, the different CPCPs are handled incorrectly. Solid waste and wastewater may contain any number of chemical and biological contaminants, making these establishments an important source of pollution (Ajuzie and Osaghae, 2012). In this context, the waste produced may adduce many pathogens to the environment, posing a serious risk in terms of human and environmental health. This work aimed to recover NFGNB from packages of hair care products, discarded as common solid waste by beauty salons and to assess their susceptibility to antibiotics and preservatives.

\section{MATERIAL AND METHODS}

\section{Beauty salons and collection of solid waste}

Samples of solid waste from opened cosmetic packages were collected from disinfected collectors distributed in seven salons in the cities of João Pessoa and Cabedelo, Brazil. Salon employees, who were responsible for the use and collection of the material had been previously instructed on how to dispose of the packages in the collectors properly to avoid further contamination of the material or to mix their contents with organic material. The accumulated waste was manually separated, using the recommendations of the Brazilian legislation (ANVISA, 2004).

Samples were taken by swabbing the inner wall of the package containing the remaining material. In containers with larger openings, the scraping was performed at the bottom, close to the grooves or slots, while with the threaded opening or flip top type of container, the scraping was conducted near the region of the caps. NFGNB were isolated (APHA et al., 2012) and staining pattern and identification were conducted as described by Vieira et al. (2011), using the Bactray III $^{\circledR}$ (Laborclin, Pinhais, Brazil).

\section{Antibiogram}

The susceptibility of the isolates to seven antibiotics used in the empirical antipseudomonal therapy scheme was tested by the Kirby-Bauer disk diffusion method (NCCLS, 2003). The tests were performed in duplicate.

\section{Susceptibility testing of preservatives}

All NFGNB resistant to at least one antibiotic were subjected to contact test with different concentrations of four substances used as preservatives in hair care product formulations to determine the minimum inhibitory concentration (MIC). The method and media used were the same as in the antibiogram. The preservative concentrations were based on biocidal concentrations already identified as to effect, given the current Brazilian legislation on the use of these substances in cosmetics (ANVISA, 2012). These tests were performed in duplicate.

\section{Data processing and statistical analysis}

To obtain the resistance ratio of an organism to the antibiotic, the number of times that this response occurred was divided by the total number of antibiotics tested. The index of resistance to preservatives was calculated in the same way. The correlation between these two indices was determined by the Pearson test and considered significant if $p<0.05$ using $\mathrm{R}$ version 3.3.3.

\section{RESULTS AND DISCUSSION}

\section{Solid waste generated by beauty salons}

A total of approximately $14 \mathrm{~kg}$ of used hair care product containers was produced by the selected beauty salons over eight weeks. Most of these packages (96.6\%) were made from plastic material, followed by metal and glass, totaling $3.4 \%$. The collection included 146 packages of 73 types of national and foreign products, especially toners or highlighters $(17.1 \%)$, shampoos $(15.8 \%)$, neutralizers $(15.1 \%)$, hair dyes $(10.3 \%)$ and bleaches (8.9\%). Other cosmetic materials (32\%) included hairsprays, hair masks, conditioners, and moisturizers. Using the Cosmetic Ingredient Review specifications (2018), eight preservatives with known toxicity or irritability were listed: DMDM hydantoin, ethylparaben, imidazolidinyl urea, methylparaben, methylisothiazolinone, propylparaben, sodium benzoate and triclosan. Among them, parabens were found in $77.7 \%$ of the products.

\section{Isolation of microorganisms}

Twelve NFGNB were recovered from the packaging and are summarized in Table 1. Three genera were identified: Burkholderia, Pseudomonas, and Aeromonas. All detected species are rods associated with opportunistic pathogens and known for their metabolic versatility by which they can easily adapt to selective pressures in their environment (Hernandéz-Montes et al., 2012).

Secondary contamination of CPCPs generally occurs due to improper manipulations by the handlers and improper storage of the products, which can result in premature deterioration of the CPCPs (Shaqra et al., 2012). Because most of the ingredients used in the formulation of CPCPs are degradable, preservatives are usually included in CPCPs to extend the stability of the end product to up to 36 months (Eck, 2006). Given this, cosmetic raw materials used for hair care provide a rich nutrient source for microorganisms, for example, fatty acids, vegetable extracts, hydrocarbons and natural polymers, synthetic or semisynthetic (Geis, 2006). 
Table 1: NFGNB recovered from the beauty salon.

\begin{tabular}{cc}
\hline Hair care products & Isolates \\
\hline Hair moisturizer & RX01 (Pseudomonas aeruginosa) \\
& RX02 (Burkholderia cepacia) \\
& RX04 (Aeromonas hydrophila) \\
& RX11 (Burkholderia cepacia) \\
& RX03 (Burkholderia cepacia) \\
Hair straightening cream & RX12 (Burkholderia cepacia) \\
& RX05 (Burkholderia cepacia) \\
Toner & RX06 (Burkholderia cepacia) \\
Conditioner & RX07 (Burkholderia cepacia) \\
Shampoo & RX08 (Pseudomonas aeruginosa) \\
& RX09 (Burkholderia pseudomaleii) \\
Hair mask & RX10 (Pseudomonas aeruginosa) \\
Highlighter &
\end{tabular}

\section{Antibiotic resistance}

Table 2 shows the results of the antibiotic susceptibility test. Six isolates showed resistance to between one and four antibiotics. Although the six other isolates were sensitive to all antibiotics tested, well-defined colonies with clear sharp edges were observed in the zone of inhibition. Invasion in the halo region was observed in RX03, RX05, and RX08 which were sensitive to gentamicin, imipenem, polymyxin B and sulfonamide.

Table 2: Number and frequency of antimicrobial resistant NFGNB and mutant subpopulation recovered from beauty salons.

\begin{tabular}{ccccc}
\hline \multirow{2}{*}{ Antibiotic } & \multicolumn{2}{c}{ Gram-negative bacilli } & \multicolumn{2}{c}{ Resistant mutant subpopulation } \\
\cline { 2 - 5 } & $\boldsymbol{n}$ & $\boldsymbol{\%}$ & $\boldsymbol{n}$ & $\%$ \\
\hline CIP & 1 & 8.3 & 2 & 16.7 \\
NOR & 3 & 25.0 & 7 & 58.3 \\
IMP & 0 & 0.0 & 3 & 25.0 \\
MER & 2 & 16.7 & 4 & 33.3 \\
GEN & 0 & 0.0 & 4 & 33.3 \\
SUL & 3 & 25.0 & 6 & 50.0 \\
POL & 5 & 41.7 & 7 & 58.3 \\
\hline
\end{tabular}

CIP-ciprofloxacin $5 \mathrm{mg} \cdot \mathrm{mL}^{-1}$, NOR-norfloxacin $10 \mathrm{mg} \cdot \mathrm{mL}^{-1}$, IMP-imipenem 10 mg.mL ${ }^{-1}$, MER-meropenem $10 \mathrm{mg} \cdot \mathrm{mL}^{-1}$, GEN-gentamicin $10 \mathrm{mg} \cdot \mathrm{mL}^{-1}$, SUL-sulfonamide $300 \mathrm{mg} \cdot \mathrm{mL}^{-1}$, POL-polymyxina B $300 \mathrm{mg} \cdot \mathrm{mL}^{-1}$.

Exposure of bacteria to different substances, among them, preserving agents, peroxides, and surfactants, however, may create an environment whereby the microbiota exhibits a high frequency of mutation, characterizing the emergence of hypermutable strains, which represent a risk (Orús et al., 2015). This is related to the occurrence of some microorganisms being resistant to different classes of substances, including antibiotics (Green et al., 2018; Xu et al., 2009). With the purity of cultures confirmed, this result may be related to the motility of the bacteria tested or the slow diffusion of the antibiotic over the agar, but the selective pressure exerted by the substances present in cosmetics should also be considered in terms of the promotion of multiresistant genotypes.
This phenomenon has already been discussed for all species detected in this study: B. cepacia (Pope et al., 2010), P. aeruginosa (Moradali et al., 2017) and A. hydrophila (Martino et al., 2013). Establishment of hypermutable strains results from the process of microbial adaptation when bacteria is inserted in a particularly hostile environment, represented in this case by inoculating the cosmetic after the breaking of the seal, in the context of secondary contamination. Additionally, according to Maciá et al. (2004), when an antibiogram reveals the presence of mutant subpopulations within the inhibition zones of three or more antibiotics, this clearly identifies hypermutable strains, as seen in isolated RX05 and RX08.

Generally, $P$. aeruginosa and $B$. cepacia are similar in their multidrug-resistance modulation systems as a result of overexpression of efflux genes promoted by mutational events, for example, the selective pressures caused by components of cosmetic formulations. As a result, a widely-specific efflux system is responsible for expelling antibiotics and, may involve different classes of molecules such as dyes, detergents, antimetabolites, organic solvents and molecules involved in quorum-sensing (Schweizer, 2003). In addition, other mechanisms may also be involved in this complex phenomenon, exemplified by expression of enzymes (Mlynarczyk et al., 2009) or change in the antibiotic target (Lambert, 2005).

RX04 and surprisingly RX01 showed resistance to polymyxin B. The polymyxins are polypeptides that interact with lipopolysaccharide (LPS), disrupting the outer membrane in Gram-negative bacteria, resulting in an increase in membrane permeability and rapid loss of cell content (Trimble et al., 2016). Some bacteria, such as B. cepacia, have intrinsic resistance to polymyxin $\mathrm{B}$, however, the susceptibility observed in some naturally sensitive microorganisms may occur due to the modification of the structure of the polysaccharide core of LPS, particularly by the addition of aminoarabinose at the 4' position of the lipid phosphate (Gunn et al., 1998).

\section{Resistance to preservatives}

Six isolates showed resistance to at least two of the tested preservatives. RX04, RX05, and RX08 proved to be the most resistant bacilli (Table 3), however, there was no correlation between resistance to preservatives and antibiotics (correlation $=$ $-15.0 \%, p=0.776$ ). This result repeated what has been observed in previous studies (Shaqra et al., 2014; Osungunna et al., 2010; Flores et al., 1997).

Table 3: Minimal inhibitory concentration of preservatives against multidrugresistant bacilli recovered from beauty salons in at least two replicates.

\begin{tabular}{cccccc}
\hline \multirow{2}{*}{ Isolates } & \multicolumn{5}{c}{ Minimal inhibitory concentration (\%) } \\
\cline { 2 - 6 } & I & M & P & M + P & T \\
\hline RX01 (Pseudomonas aeruginosa) & $\mathrm{S}$ & $\mathrm{S}$ & 0.38 & 3.00 & $\mathrm{~S}$ \\
RX02 (Burkholderia cepacia) & 1.50 & $\mathrm{~S}$ & $\mathrm{~S}$ & 3.00 & 1.50 \\
RX03 (Burkholderia cepacia) & 1.50 & 1.50 & 0.75 & 0.38 & 1.50 \\
RX04 (Aeromonas hydrophila) & 6.00 & $\mathrm{R}$ & $\mathrm{R}$ & $\mathrm{R}$ & 6.00 \\
RX05 (Burkholderia cepacia) & 6.00 & $\mathrm{~S}$ & 0.38 & $\mathrm{R}$ & 6.00 \\
RX08 (Pseudomonas aeruginosa) & 6.00 & $\mathrm{~S}$ & 1.50 & $\mathrm{R}$ & 6.00 \\
\hline
\end{tabular}

Range of concentration: imidazolidinyl urea (I): 6.0-0.38\%; methylparaben (M), propylparaben (P) and triclosan (T): 3.0-0.19\%. Letters $\mathrm{R}$ and $\mathrm{S}$ indicate that isolates were resistant or susceptible to all concentrations tested. 
In the case of imidazolidinyl urea, only RX01 was sensitive. Given this, 5 isolates exhibited a disturbing resistance pattern as their MIC ranged from 2.5 to 10 times the reference value, $0.6 \%$ (ANVISA, 2012), inferring that the microorganisms had already adapted to the presence of the new generations of preservatives.

Imidazolidinyl urea is a formaldehyde-releaser found in $15 \%$ of CPCPs (Geis et al., 2006). Generally, it is used in association with other preservatives in the cosmetic industry, particularly in formulations intended for skin care and the eye area or those areas that remain in contact with mucous for hours (Noureddine et al., 2013). Its mechanism of action involves alkalinization of the amino or sulfhydryl groups of proteins or of the nitrogen ring in the purine bases, being an effective biocide against Gram-negative bacilli in concentrations greater than $0.5 \%$. The maximum concentration allowed in CPCPs, however, is only $0.6 \%$ in Brazil (ANVISA, 2012).

Most of the isolates were susceptible to triclosan in all concentrations tested, with the exception of RX04, whose MIC was detected at $1.5 \%$. With respect to parabens, methylparaben was the most efficient as a biocidal agent compared to propylparaben or an association of the two. RX04, RX03, RX08, and RX05 exhibited the most significant resistance profiles. For example, RX04 did not form halos in all parabens concentrations tested. Traditionally, triclosan and parabens are considered of low toxicity and are found in more than $85 \%$ of the CPCPs (Cosméticos and Perfumes, 2008). However, these substances are highly absorbed when swallowed and there is a known risk of multiple adverse effects when in contact with skin, mucosa, and conjunctiva (OcañaGonzález et al., 2015).

In concentrations ranging from 0.5 to $3 \%$, triclosan acts by inhibiting the synthesis of fatty acids and therefore presents a broad spectrum of activity against bacteria and fungi (Heath et al., 1999). However, due to the mutagenic and genotoxic nature of this compound (Wang et al., 2017), the maximum concentration allowed for use in cosmetics is $0.3 \%$ (ANVISA, 2012), i.e. less than five times the MIC determined, which may justify the isolation of RX04 in the capillary moisturizer.

On the other hand, parabens in the range between 0.015 and $0.3 \%$ are believed to block the electron and membrane transport systems (Denyer, 1995). Considering their toxicity, these compounds separately are allowed to be at the most $0.4 \%$ in formulations, reaching $0.8 \%$ when combined with other parabens (ANVISA, 2012). This group is more effective against filamentous fungi, yeasts, and Gram-positive bacteria, but less active against Gram-negative caused by intrinsic resistance mechanisms, which may explain the test results (Crovetto et al., 2017).

Besides the discussion on toxicity, the possibility that parabens can cause endocrine disruption must be considered. In this case, preservatives block the receptors of naturally occurring hormones, which alters the metabolism of the cells and synthesis and distribution of other hormones. Medical conditions have been reported in the literature as being related to parabens, such as increased incidence of breast, testis and prostate cancer; malignant melanoma; endometriosis and reduced volume of semen (Noureddine et al., 2013). Additionally, in animals, alterations in egg hatching, male feminization and changes in the immune system have already been observed due to preservatives (Bila and
Dezotti, 2007). Given the toxic and endocrine disruption effects, many countries, including Brazil, have limited the maximum concentration of these compounds to well below 1\% (ANVISA, 2012).

An adult uses on average nine CPCPs per day, with formulations that may result in 126 different chemical compounds (Bocca et al., 2014). Given the risks of pollution from discharge or biological contamination related to cosmetic waste, beauty salons should be recognized as a potential environmental contamination source. It is noteworthy that these types of establishments are still an unexplored field of research. There is a current gap in the literature regarding the quality and risk of waste produced by beauty salons when compared to common issues such as air quality of the exposed public in confined spaces (Raymer et al., 2009; Mounier-Geyssant et al., 2006), labor conditions (Vogel, 2011), disease transmission by fomites (Atei et al., 2010) and quality of service and customer satisfaction (Yim et al., 2007).

This work was the first study in the literature that has explored the microbiological quality of the waste produced in these establishments in Northeastern Brazil. The project for which this work was conceived received the Elo-Cidadão Award 2015, acknowledged by the Dean of Extension and Community Affairs of the Federal University of Paraiba.

\section{CONCLUSIONS}

This study highlights the risk that opportunistic pathogens found in cosmetic preparations and their packaging discarded as common domestic waste pose for human and environmental health. Besides evoking the need to change the handling practices of cosmetics in beauty salons, this study demonstrates that some bacteria recovered from cosmetic packaging are resistant to antibiotics and certain classes of preservatives, demanding the need of new preservatives, as well as the development of policies for the appropriate management of these residues.

\section{ACKNOWLEDGEMENT}

The authors acknowledge $\mathrm{CNPq}$ and UFPB for the financial support, as well as the owners of the beauty salons for consent to use of their establishments for the purposes of this work. The English text of this paper has been revised by Sidney Pratt, Canadian, MAT (The Johns Hopkins University), RSAdipTESL (Cambridge University).

\section{CONFLICT OF INTERESTS}

The authors declare that no conflict of interest is associated with this work.

\section{REFERENCES}

ABIHPEC - Brazilian Association of Cosmetic and Personal Care Products Industry. 2017. Available at: http:abihpec.org.br [accessed 24 February 2018].

Ajuzie CU, Osaghae BA. The bacterial and physicochemical properties of hair salon wastewater and contaminated soil in Benin metropolis. Afr J Biotechnol, 2012; 10:2066-2069.

ANVISA - National Sanitary Surveillance Agency. 2012. Resolução da Diretoria Colegiada - RDC n. 29 de 01 de junho de 2012. Distrito Federal, Brasília.

ANVISA - National Sanitary Surveillance Agency. 2005 Resolução da Diretoria Colegiada - RDC n. 211 de 14 de julho de 2005. 
Distrito Federal, Brasília.

ANVISA - National Sanitary Surveillance Agency. 2004.

Resolução da Diretoria Colegiada - RDC n. 306 de 7 de dezembro de 2004. Distrito Federal, Brasília.

APHA, AWWA, WEF. 2012. Standard methods for the examination of water and wastewater. Baltimore, USA: APHA, AWWA, WEF.

Atei B, Shirani K, Alavian SM, Ataie M. Evaluation of knowledge and practice of hairdressers in women's beauty salons in Isfahan about hepatitis B, hepatitis C, and AIDS in 2010 and 2011. Hepat Mon, 2013; 13:1-6.

Bila DM, Dezotti M. Endocrine disrupters in the environment: part 1 - effects and consequences. Quim Nova, 2007; 30:651-666.

Bocca B, Pino A, Alimonti A, Forte G. Toxic metals contained in cosmetics: a status report. Regul Toxicol Pharmacol, 2014; 68:447-467.

Bu Q, Wang B, Huang J, Deng S, Yu G. Pharmaceuticals and personal care products in the aquatic environment in China: a review. J Hazard Mater, 2013; 262:189-211.

Cosmetic Ingredient Review. Available at: http://www.cir-safety. org [accessed 20 March 2018].

Cosméticos \& perfumes. Conservantes utilizados em cosméticos. Cosm Perf, 2008; 50:28-52.

Crovetto SI, Moreno E, Dib AL, Espigares M, Espigares E. Bacterial toxicity testing in antibacterial activity of parabens. Toxicol Environ Chem, 2017; 99:858-868.

Denyer SP. Mechanisms of action of antibacterial biocides. Int Biodeterior Biodegrad, 1995; 36:227-245.

Eck KS. 2006. Preservative efficacy testing during formula development and stability tests. In: Orth DS, Kabara JJ, Denyer SP, Tan SK, ed. Cosmetic and drug microbiology. Boca Raton: CRC Press 109-122.

Fendall LS, Sewell MA. Contributing to marine pollution by washing your face: microplastics in facial cleansers. Mar Pollut Bull, 2009; 58:1225-1228.

Flores M, Morillo M, Crespo ML. Deterioration of raw materials and cosmetic products by preservative resistant microorganisms. Int Biodeterior Biodegrad, 1997; 40:157-160.

\& Francis.

Geis PA. 2006. Cosmetic microbiology. New York, US: Taylor

Green AE, Amézquita A, Le-Marc Y, Bull MJ, Connor TR, Mahenthiralingam E. The consistent differential expression of genetic pathways following exposure of an industrial Pseudomonas aeruginosa strain to preservatives and a laundry detergent formulation. FEMS Microbiol Let, 2018; 365:fny062. doi: 10.1093/femsle/fny062.

Gunn JS, Lim KB, Krueger J, Kim K, Guo L, Hackett M, Miller SI. Pmr-A-Pmr-B regulated genes necessary for 4-aminoarabinose lipid A modification and polymyxin resistance. Mol Microbiol, 1998; 27:11711182.

Heath RJ, Rubins JR, Hollands DR, Zhang E, Snows ME, Rock CO. Mechanism of triclosan inhibition of bacterial fatty acid synthesis. J Biol Chem, 1999; 274:11110-11114.

Hernandéz-Montes G, Argüello JM, Valderrama B. Evolution and diversity of periplasmatic proteins involved in copper homeostasis in gamma proteobacteria. BMC Microbiol, 2012; 12:1-14.

IBOPE - Brazilian Institute for Public Opinion and Statistics. 2017. Available at: http://www.ibope.com.br [accessed 10 April 2017].

Lambert PA. Bacterial resistance to antibiotics: modified target sites. Adv Drug Deliv Rev, 2005; 57:1471-1485.

Lin D, Zhou Q, Xie X, Liu Y. Potential biochemical and genetic toxicity of triclosan as an emerging pollutant on earthworms (Eisenia foetida). Chemosphere, 2010; 81:1328-1333.

Maciá MD, Borrel N, Pérez JL, Oliveir A. Detection and susceptibility testing of hypermutable Pseudomonas aeruginosa strains with the Etest and disk diffusion. Antimicrob Agents Chemother, 2004; 48:2665-2672.

Martino ME, Fasolato L, Montemurro F, Novelli E, Cordazzo B. Aeromonas spp. ubiquitous or specialized bugs? Environ Microbiol, 2013;
16:1005-1018.

Mlynarczyk G, Sawicka-Grzelak A, Szymanek K, Buczkowska T, Pazik J, Durlik M, Pacholczyk M, Lagiewska B, Chmura A, Paczek L, Mlynarczyk A. Resistance to carbapenems among Pseudomonas aeruginosa isolated from patients of transplant wards. Transplant Proc, 2009; 41:32503260 .

Moradali MF, Ghods S, Rehm BHA. Pseudomonas aeruginosa lifestyle: a paradigm for adaptation, survival and persistence. Front Cell Infect Microbiol, 2017; 7:1-29. doi: 10.3389/fcimb.2017.00039.

Mounier-Geyssant E, Oury V, Mouchot L, Paris C, ZmirouNavier D. Exposure of hairdressing apprentices to airborne hazardous substances. Environ Health, 2006; 5:1-8.

NCCLS. 2003. Methods for Dilution Antimicrobial Susceptibility Tests for bacteria that grow aerobically. Wayne, USA: NCCLS.

Nkansah, A, Opoku, F, Ephraim, JH, Wemegah, DD, Tetteh, LPM. Characterization of beauty salon wastewater from Kwame Nkrumah University of Science and Technology, Kumasi, Ghana, and its surrounding communities. Environ Health Insights, 2016; 10:147-154.

Noureddine H, Kebir B, Zahia B, Nadjib R. Erythrocyte toxicities of imidazolidinyl urea and diazolidinyl urea. J Mat Sci Eng B, $2013 ; 3: 445-451$.

Ocaña-González JA, Villar-Navarro M, Ramos-Pyán M, Fernández-Torres R, Bello-López MA. New developments in the extraction and determination of parabens in cosmetics and environmental samples. A review. Anal Chim Acta, 2015; 9:1-15.

Orús P, Gómez-Perez L, Leranoz S, Berlanga M. Increasing antibiotic resitance in preservative-tolerant bacterial strains isolated from cosmetic products. Int Microbiol, 2015: 18:51-59.

Osungunna MO, Oluremi BB, Adetuyi A. Bacteriological and antibiotic sensitivity patterns of bacterial isolates from creams and lotions hawked in Sagamu, Ogun State. Pakistan J Nut, 2010; 9:773-775.

Pope CF, Gillespie SH, Moore JE, McHugh TD. Approaches to measuring the fitness of Burkholderia cepacia complex isolates. J Med Microbiol, 2010; 59:679-686.

Raymer JH, Akland G, Johnson TR, Long T, Michael L, Cauble $\mathrm{L}, \mathrm{McCombs}$ M. Microenvironmental characteristics important for personal exposures to aldehydes in Sacramento, CA, and Milwaukee, WI. Atmos Environ, 2009; 43:3910-3917.

Richardson SD. Water analysis: emerging contaminants and current issues. Anal Chem, 2007: 79:4295-4324.

Schweizer HP. Efflux as a mechanism of resistance to antimicrobials in Pseudomonas aeruginosa and related bacteria: unanswered questions. Genet Mol Res, 2003; 2:48-62.

Shaqra QMA, Al-Gromm RM. Microbiological quality of hair and skin cosmetics manufactured in Jordan. Int Biodeter Biodegr, 2012; 69:69-72.

Shaqra QMA, Al-Momani W, Al-Groom RM. Susceptibility of some bacterial contaminants recovered from commercial cosmetics in Jordan to preservatives and antibiotics. Trop J Pharm Res, 2014; 13:255-259.

Trimble MJ, Patrik Mlynárčik P, Kolář M, Hancock REW. Polymyxin: alternative mechanisms of action and resistance. Cold Spring Harb Perspect Med, 2016; 6:1-22. doi: 10.1101/cshperspect.a025288.

Vieira CDV, Carvalho MAR, Cussiol NAM, Alvarez-Leite ME, Santos SG, Gomes RMF, Silva MX, Nicoli JR, Farias LM. Count, identification, and antimicrobial susceptibility of bacteria recovered from dental solid waste in Brazil. Waste Mange, 2011; 31:1327-1332.

Vogel L. US legislators propose crackdown on toxic cosmetics. CMAJ, 2011; 183:E1169-E1170.

Wang Z, Li X, Klaunig JE. Investigation of the mechanism of triclosan induced mouse liver tumors. Regul Toxicol Pharmacol, 2017; 86:137-147.

$\mathrm{Xu} \mathrm{J}, \mathrm{Wu} \mathrm{L}, \mathrm{Chang}$ AC. Degradation and adsorption of selected pharmaceuticals and personal care products (PPCPs) in agricultural soils. Chemosphere, 2009; 77:1299-1305.

Yim CK, Chan KW, Hung K. Multiple reference effects in services evaluations: roles of alternative attractiveness and self-image 
congruity. J Retailing, 2007; 1:147-157.

Zapka CA, Campbell EJ, Maxwell SL, Gerba CP, Dolan MJ, Arbogast JW, Macinga DR. Bacterial hand contamination and transfer after use of contaminated bulk-soap-refillable dispensers. Appl Environ Microbiol, 2011; 77:2898-2904.

Zulaikha RS, Norkhadijah SIS, Praveena SM. Hazardous ingredients in cosmetics and personal care products and health concern: a review. Pub Health Res, 2015; 5:7-15.
How to cite this article:

Martins RX, Viana AAG, Ferreira GF, Cavalcanti TG, Amaral LPG, Travassos RDA, Vasconcelos U. Preservative and antimicrobial susceptibility of non-fermenting bacilli recovered from solid waste of beauty salons in Brazil. J App Pharm Sci, 2018; 8(06): 169-174. 